OPEN ACCESS

Edited by:

Lai-Chang Zhang,

Edith Cowan University, Australia

Reviewed by:

Chirag Dhirajlal Rabadia,

Edith Cowan University, Australia

Yi Yang,

University of Shanghai for Science and Technology, China

*Correspondence:

Frédéric Prima

frederic.prima@chimieparistech.psl.eu

${ }^{\dagger}$ Present address:

Yolaine Danard,

Université Paris Est, Institut de Chimie

et des Matériaux Paris-Est

(UMR 7182), CNRS, UPEC, Thiais,

France

Specialty section:

This article was submitted to

Structural Materials,

a section of the journal

Frontiers in Materials

Received: 29 April 2020

Accepted: 29 June 2020

Published: 28 July 2020

Citation:

Danard Y, Sun F, Gloriant T, Freiherr Von Thüngen I, Piellard $M$ and

Prima F (2020) The Influence

of Twinning on

the Strain-Hardenability in TRIP/TWIP

Titanium Alloys: Role

of Solute-Solution Strengthening.

Front. Mater. 7:240.

doi: 10.3389/fmats.2020.00240

\section{The Influence of Twinning on the Strain-Hardenability in TRIP/TWIP Titanium Alloys: Role of Solute-Solution Strengthening}

\author{
Yolaine Danard ${ }^{1 \dagger}$, Fan Sun ${ }^{1}$, Thierry Gloriant ${ }^{2}$, Immanuel Freiherr Von Thüngen ${ }^{3}$, \\ Michaël Piellard ${ }^{3}$ and Frédéric Prima ${ }^{1 *}$ \\ ${ }^{1}$ Institut de Recherche de Chimie Paris, Chimie ParisTech, PSL Research University, UMR 8247, CNRS, Paris, France, \\ 2 INSA Rennes, Univ Rennes, ISCR, CNRS - UMR 6226, Rennes, France, ${ }^{3}$ SAFRAN TECH, Châteaufort, France
}

Transformation Induced Plasticity and Twinning Induced Plasticity (TWIP) titanium alloys are well-known to display a good combination of strain-hardenability and ductility. However, a large range of strain-hardening rates, which cannot be predicted by the actual design method based on electronic parameters, is obtained. In order to explain this wide range of properties, two different alloys displaying a large difference of strain-hardening rates, but similar chemical stability, have been studied and compared: Ti-12Mo and Ti-8.5Cr-1.5Sn (in wt\%). Evolution of both twin size and density during in situ tensile tests has been followed by SEM/electron backscatter diffraction mapping, and two distinct behaviors can be highlighted: the growth of existing twins (Ti-12Mo) and the nucleation of new twins (Ti-8.5Cr-1.5Sn) upon loading. The last one may lead to an improvement of the dynamic Hall-Petch effect by multiplication of twin/matrix interfaces, with subsequent improvement of the macroscopic strain-hardening. It is thought that this competition may be related to the crystal lattice distortion induced by the alloying elements and the subsequent reduction of the migration velocity of the twin/matrix interfaces.

Impact Statement: This work reports on distinct behaviors of mechanical twins in TRIP/TWIP titanium alloys, highlighting for the first time a competition between growth of existing twins and nucleation of additional twins upon loading. This effect is assumed to be due to the solute-strengthening effect in the studied alloys and modify, as a consequence, the strain-hardenability of the TRIP/TWIP alloys.

Keywords: titanium alloys, $\beta$-metastable, TRIP/TWIP effects, strain-hardening, in situ investigation, lattice distortion

\section{INTRODUCTION}

For a few years, strain-transformable titanium alloys have attracted a lot of attention, thanks to their specific mechanical properties, allowing a breakthrough from usual $\beta$-metastable titanium alloys mechanical properties (Marteleur et al., 2012; Sun et al., 2013; Brozek et al., 2016; Gao et al., 2018; Ren et al., 2018; Sadeghpour et al., 2018; Lilensten et al., 2019). The combination of Transformation Induced Plasticity (TRIP) and Twinning Induced Plasticity (TWIP) effects is now known to lead to 
a drastic improvement of both strain-hardening and ductility compared to "classical" titanium alloys. The occurrence of the TRIP and/or TWIP effects in Ti-alloys depends on the chemical stability of the $\beta$-phase, which is influenced by the alloying elements and the grain orientation depending on the tensile axis. Indeed, Lilensten et al. (2019) showed that the main deformation mechanism in a grain can be predicted by the Schmid factor calculation. So far, most of the design strategies for TRIP/TWIP titanium alloys have been almost exclusively based on the " $\mathrm{d}$ electron"-guided approach using the Bo-Md (where Bo stands for average bond order and $\mathrm{Md}$ for average d-orbital energy) method in order to predict the $\beta$-phase chemical stability (AbdelHady et al., 2006). This tool has clearly shown its efficiency in designing new strain-transformable alloys with a surprising robustness but failed in predicting the strain-hardenability of the developed alloys (which is spread over a large range) because several additional microstructural parameters may be involved. Yet, strain-hardening is generally attributed to both a dynamic Hall-Petch effect mainly and to a "mechanical contrast" effect (Sun et al., 2015; Brozek et al., 2016). So far, the total twinned fraction has been used as the main consistent variable to characterize the twinning behavior for different TWIP alloys. However, recent researches by Zhao et al. $(2019,2020)$ confirmed that the key microstructural parameter determining the TWIPbased hardenability is the dynamically reduced intertwin spacing, which is as a function of both the twin-density and twin-fraction. This raises new fundamental questions closely related to twin evolution mode upon loading, that is, nucleation versus growth of twins as dominant mechanism to reach a given fraction of twins. Therefore, further optimization approaches for highly strainhardenable alloys now require an improved knowledge to better understand the "twinability" mode of TRIP/TWIP alloys.

To exemplify these statements, two alloys from the literature exhibiting a large difference of strain-hardening rate have been investigated: Ti-12Mo (Marteleur et al., 2012; Sun et al., 2013) and $\mathrm{Ti}-8.5 \mathrm{Cr}-1.5 \mathrm{Sn}$ (Brozek et al., 2016) (both in wt\%). It is worth noting that the two alloys display isostability with respect to the couple of Bo/Md electronic parameters for design. The active deformation mechanisms have been extensively investigated previously in these two alloys by the same authors (Marteleur et al., 2012; Sun et al., 2013; Brozek et al., 2016), highlighting a stress-induced precipitation of $\alpha$ " martensite and a dense network of $\{332\}<113>$ twins. On this basis, it is worth noting that the present work is focused on the "twinability" contribution to the macroscopic strain-hardening. The deformed twinned microstructures have been then correlated with their observed strain-hardening rates. Based on these observations, two different families of "twinability modes" have been evidenced. In order to initiate promising routes toward improved strainhardenability, this article proposes to take into account the solute strengthening nature of the targeted alloying elements in the design approach. Thus, the main objective of this work is to bring a first proof of concept related to the close relation between a "lattice distortion" parameter, directly depending on the solution-strengthening ability of alloying elements, and the strain-hardenability of the designed strain-transformable titanium alloys.

\section{MATERIALS AND METHODS}

Small cast ingots of the studied $\mathrm{Ti}-12 \mathrm{Mo}$ (in wt $\%$ ) and $\mathrm{Ti}-8.5 \mathrm{Cr}-1.5 \mathrm{Sn}$ (in $\mathrm{wt} \%$ ) alloys were prepared by arcmelting furnace under high-purity Ar atmosphere. Element quantification had been performed for both alloys by EDX analysis (Rabadia et al., 2018b, 2019). Results are given in Table 1.

After a first stage of recrystallization heat treatment at $1,173 \mathrm{~K}$ under air for $1.8 \mathrm{ks}$, followed with a water-quenching, slide-cut samples were cold rolled until $0.6 \mathrm{~mm}$ of thickness (corresponding to $85 \%$ of reduction). In order to keep a similar grain size between the two materials, sheets were re-heat treated in the $\beta$-domain at adequate temperatures: $1,173 \mathrm{~K}$ during $1.8 \mathrm{ks}$ for $\mathrm{Ti}-12 \mathrm{Mo}\left(T_{\beta}=1,073+100 \mathrm{~K}\right)$ and at $1,123 \mathrm{~K}$ $\left(T_{\beta}=1,013+110 \mathrm{~K}\right)$ during $1.8 \mathrm{ks}$ for $\mathrm{Ti}-8.5 \mathrm{Cr}-1.5 \mathrm{Sn}$ under high vacuum and then water-quenched (Figure 1). As a final microstructure, both alloys display a fully $\beta$ structure with an average grain size of $100 \mu \mathrm{m}$. Tensile specimens were prepared by wire EDM, with gage dimensions of $50 \mathrm{~mm} \times 5 \mathrm{~mm} \times 0.6 \mathrm{~mm}$. Three uniaxial tensile tests by alloy, showing equivalent results, were carried out along the rolling direction at room temperature using an INSTRON 5966 machine with a $10-\mathrm{kN}$ load cell and an external extensometer with a gage length of $10 \mathrm{~mm}$, at a strain rate of $1.7 \times 10^{-3} \mathrm{~s}^{-1}$. In situ SEM tensile tests were performed using a Proxima 100-Micromecha machine on samples with dimensions $35 \mathrm{~mm} \times 2 \mathrm{~mm} \times 0.6 \mathrm{~mm}$ prepared by electropolishing. Electron backscatter diffraction (EBSD) scans were collected during straining using a field emission gun scanning electron microscope operating at $20 \mathrm{kV}$, with step size of $0.8 \mu \mathrm{m}$. Electron backscatter diffraction scans were recorded at four stages of strain: 5, 7, 10, and $15 \%$. Electron backscatter diffraction scans at the last stage of strain (15\%) were recorded on the unloaded state after a slight electropolishing step to remove the surface relief of a few microns. The different deformation steps have been selected in order to cover a regular increase of strain from $5 \%$, where twins can be indexed by EBSD analysis, to $15 \%$, where indexation starts to be more complex and tricky by EBSD method, due to the strong crystal distortion induced by mechanical twinning.

\section{RESULTS AND DISCUSSION}

\section{Mechanical Properties and Initial Microstructures}

The design strategy of both $\mathrm{Ti}-8.5 \mathrm{Cr}-1.5 \mathrm{Sn}$ and $\mathrm{Ti}-12 \mathrm{Mo}$ alloys has been performed based on "d-electron" Bo-Md maps

TABLE 1 | EDX analyses of the Ti-12Mo and the Ti-8.5Cr-1.5Sn alloys.

\begin{tabular}{lcccc}
\hline & Ti (wt\%) & Mo (wt\%) & Cr (wt\%) & Sn (wt\%) \\
\hline Ti-12Mo & Balance & 11.9 & - & - \\
Ti-8.5Cr-1.5Sn & Balance & - & 8.4 & 1.58
\end{tabular}




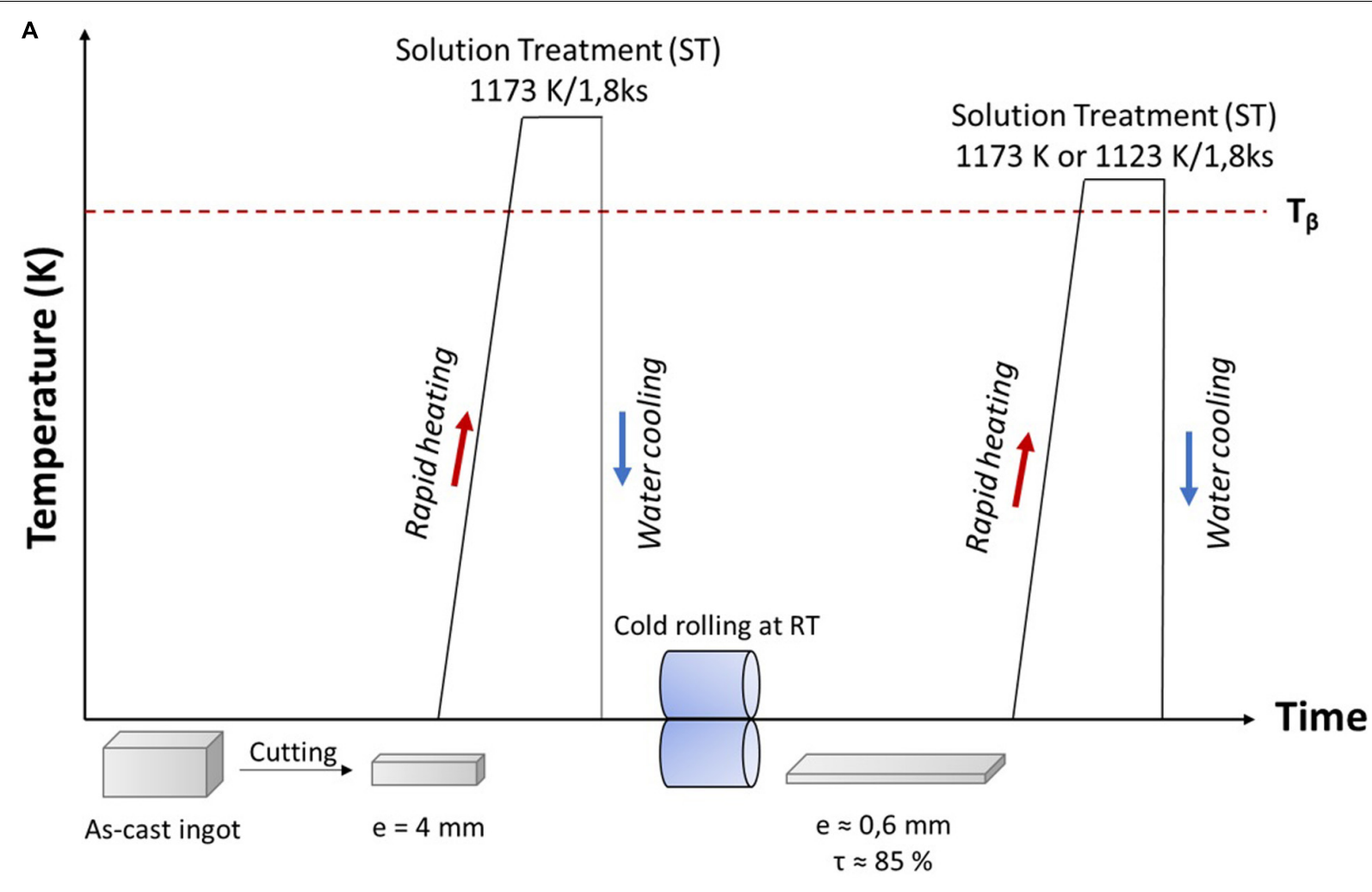

B

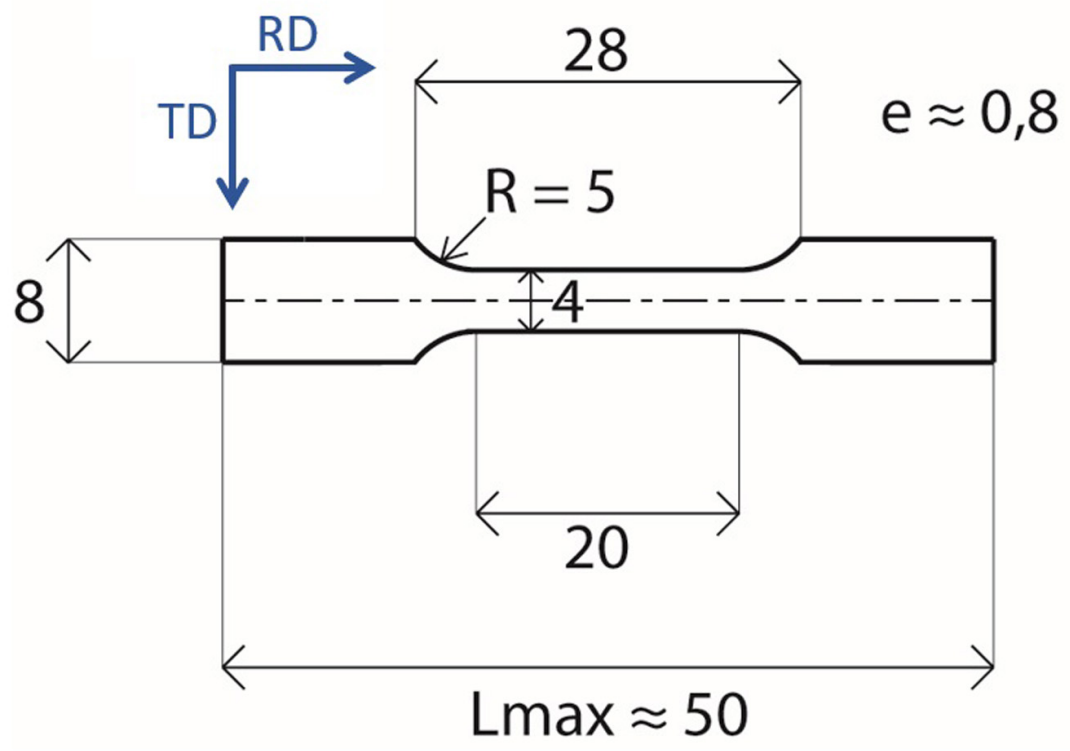

FIGURE 1 | (A) Scheme of the Ti-12Mo and Ti-8.5Cr-1.5Sn thermomechanical sequences. (B) Scheme of tensile specimen dimensions.

(Rabadia et al., 2018a). As stated in various previous works (Marteleur et al., 2012; Sun et al., 2013; Brozek et al., 2016), the figurative position of the two alloys has been carefully set to be on the $\mathrm{Md}=\mathrm{RT}$ transition line on the Bo/Md stability map, to reach combined TRIP and TWIP effects upon loading (Figure 2).

After treatment in the $\beta$ field, both alloys show a fully $\beta$ recrystallized microstructure. It is worth noting that the two investigated materials display similar average grain size $(100 \mu \mathrm{m})$ and texture (mainly $\gamma$-fiber texture) (Figure 3).

Tensile true stress-true strain curves and associated strain-hardening rates as a function of strain for $\mathrm{Ti}-12 \mathrm{Mo}$ (in red) and $\mathrm{Ti}-8.5 \mathrm{Cr}-1.5 \mathrm{Sn}$ (in blue) are presented in Figure 4 and the tensile properties in Table 2. Young moduli have been calculated from the extensometer measurements and 


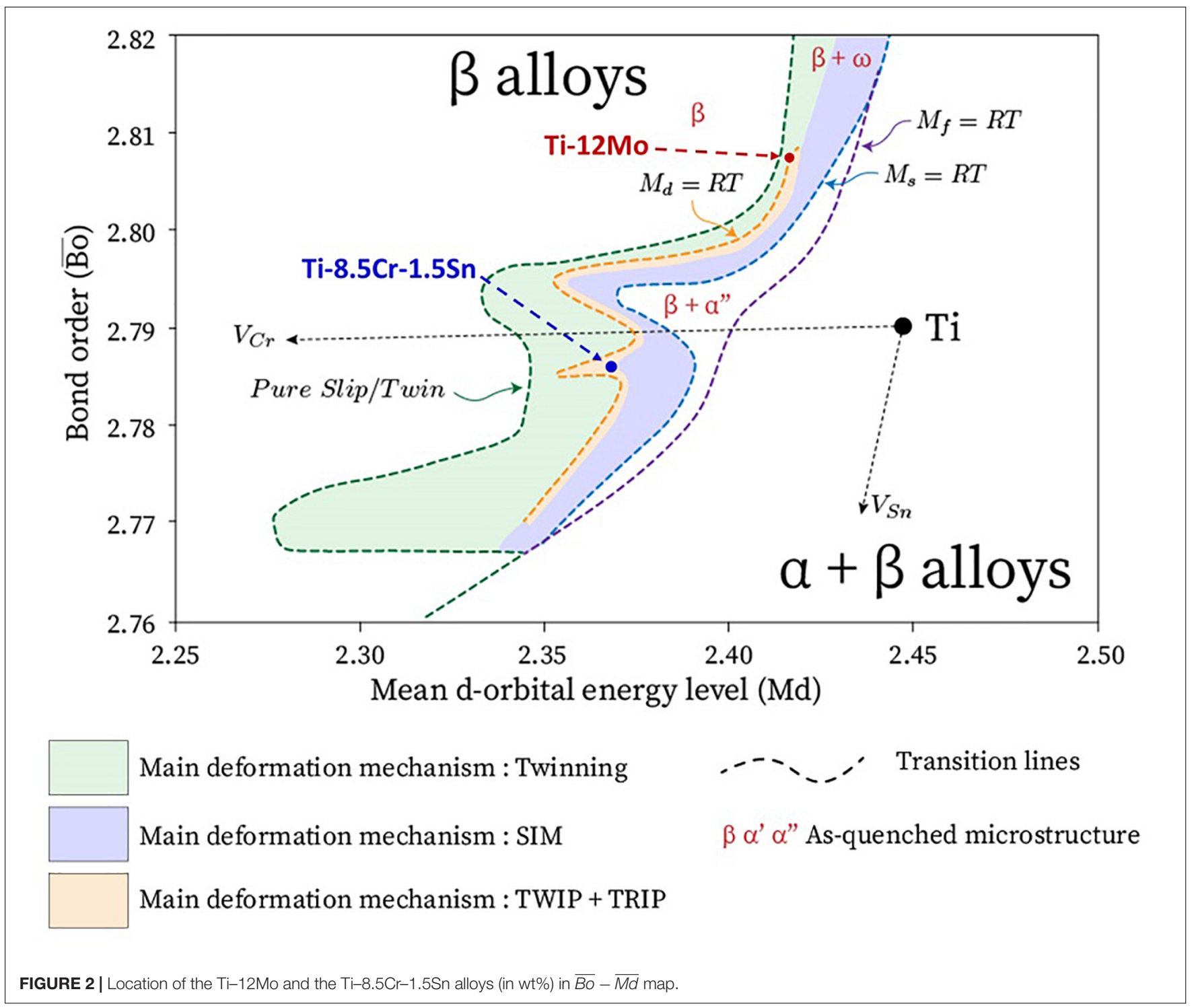

corresponded to the linear slope. Work-hardening rate have been calculated from the true stress-strain curves.

It can be noted that the measured elastic moduli are very similar between the two alloys, and hence their shear moduli should be similar as well. Both alloys display classical (and similar in shape) TRIP/TWIP stress-strain tensile curves with several apparent successive stages, namely, the more or less marked plateau from their plastic threshold to $\varepsilon \approx 0.1$, followed by a strain-hardening increase, presumably associated to the $\alpha$ " transformation as reported elsewhere (Miyazaki et al., 1981; Lilensten et al., 2019) and finally a smooth and stable decrease up to fracture. It is worth noting that the role of $\alpha^{\prime \prime}$ stress-induced precipitation in the overall shape of the strain-hardening profile is actually far to be negligible. The $\alpha^{\prime \prime}$ precipitation may provide a notable contribution to the observed macroscopic strain-hardening, inducing a "plateau" shortly followed by a strong "bump" on the stress-strain curves. This bump can be interpreted as the elastic deformation contribution of the newly formed $\alpha^{\prime \prime}$ martensite to the overall strain-hardening (then, playing the role of an "elastic inclusion"), which ends when the martensite itself enters into plasticity (at $\varepsilon \approx 0.1$, for these two alloys). Comparing the two curves, it can be observed that the "bump" is actually much higher on the $\mathrm{Ti}$ $12 \mathrm{Mo}$ alloy than on the $\mathrm{Ti}-8.5 \mathrm{Cr}-1.5 \mathrm{Sn}$ alloy. This suggests a much higher volume fraction of stress-induced precipitated $\alpha^{\prime \prime}$ on deformed Ti-12Mo. This is actually clearly consistent with the published work on the two alloys (Marteleur et al., 2012; Sun et al., 2013; Brozek et al., 2016). This fact is noticeable and has been kept in mind in the course of this work. However, this is not the main scope of this article because it can be observed that, despite the larger contribution of $\alpha^{\prime \prime}$ precipitation in Ti-12Mo strain-hardening rate, the strain-hardenability is kept to a much higher level on $\mathrm{Ti}-8.5 \mathrm{Cr}-1.5 \mathrm{Sn}$ alloy, combined with a higher yield stress. It is presently thought that this difference of strain-hardenability can be interpreted in terms of "twinability mode," related to the dominant mechanism 
A
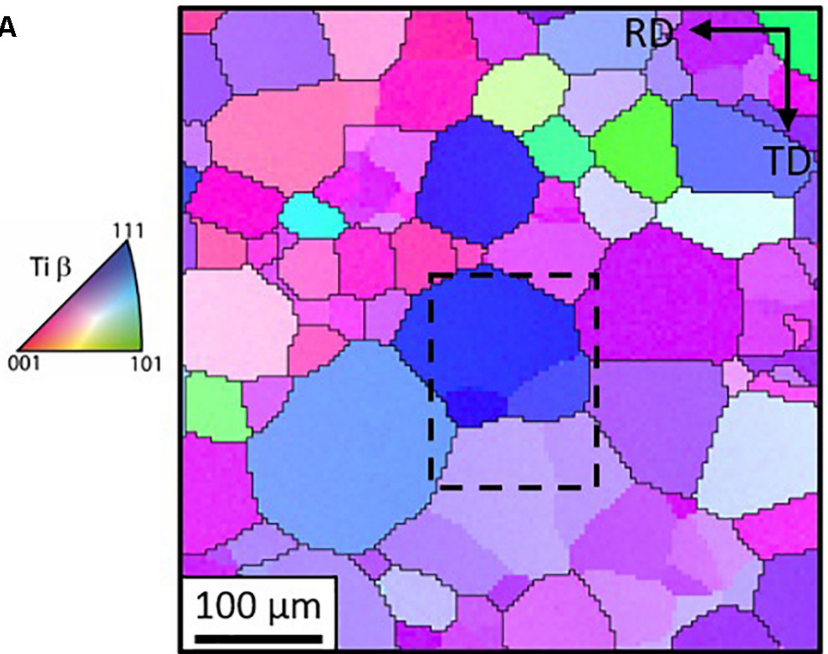

B

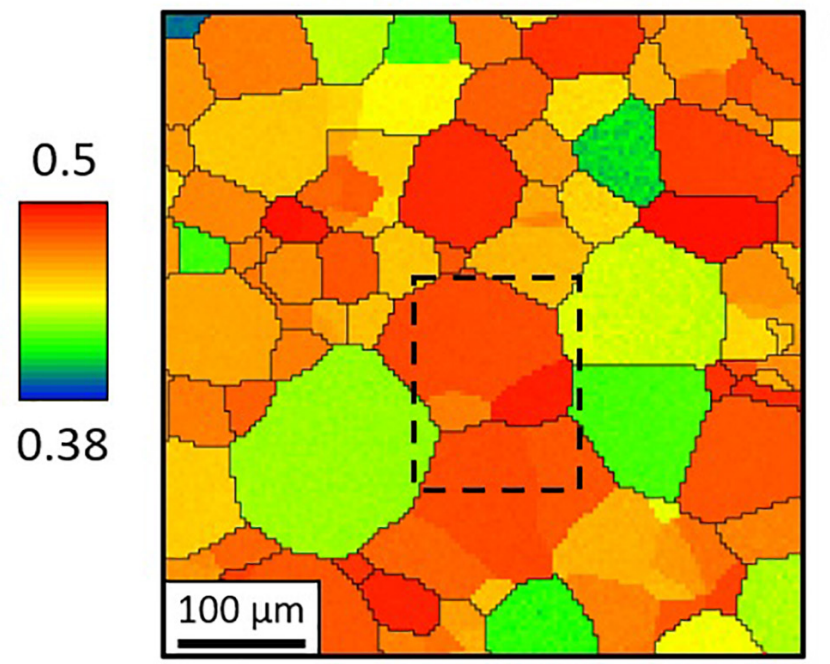

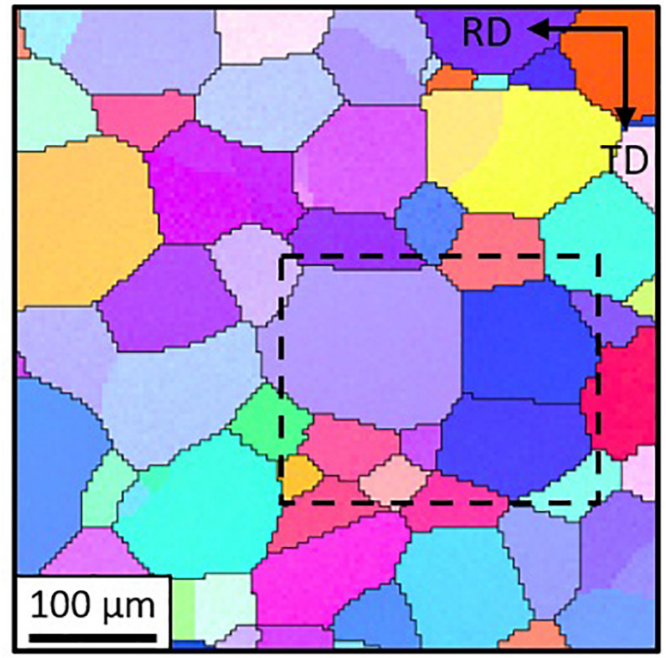

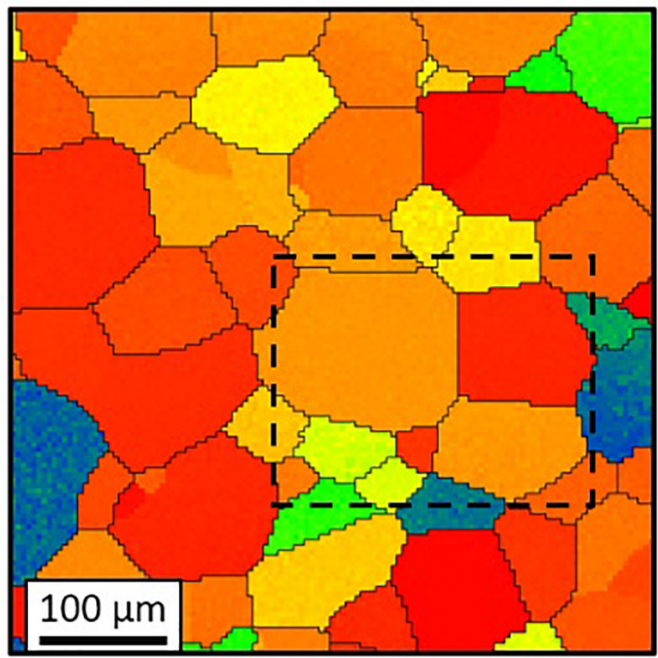

FIGURE 3 | Electron backscatter diffraction maps of initial microstructures before deformation of (A,B) Ti-12Mo and (C,D) Ti-8.5Cr-1.5Sn. (A,C) inverse pole figure (IPF) along the normal direction (ND) and (B,D) Schmid factor maps for the $\{332\}<113>$ system. Studied areas during in situ tensile tests are indicated by dashed lines.
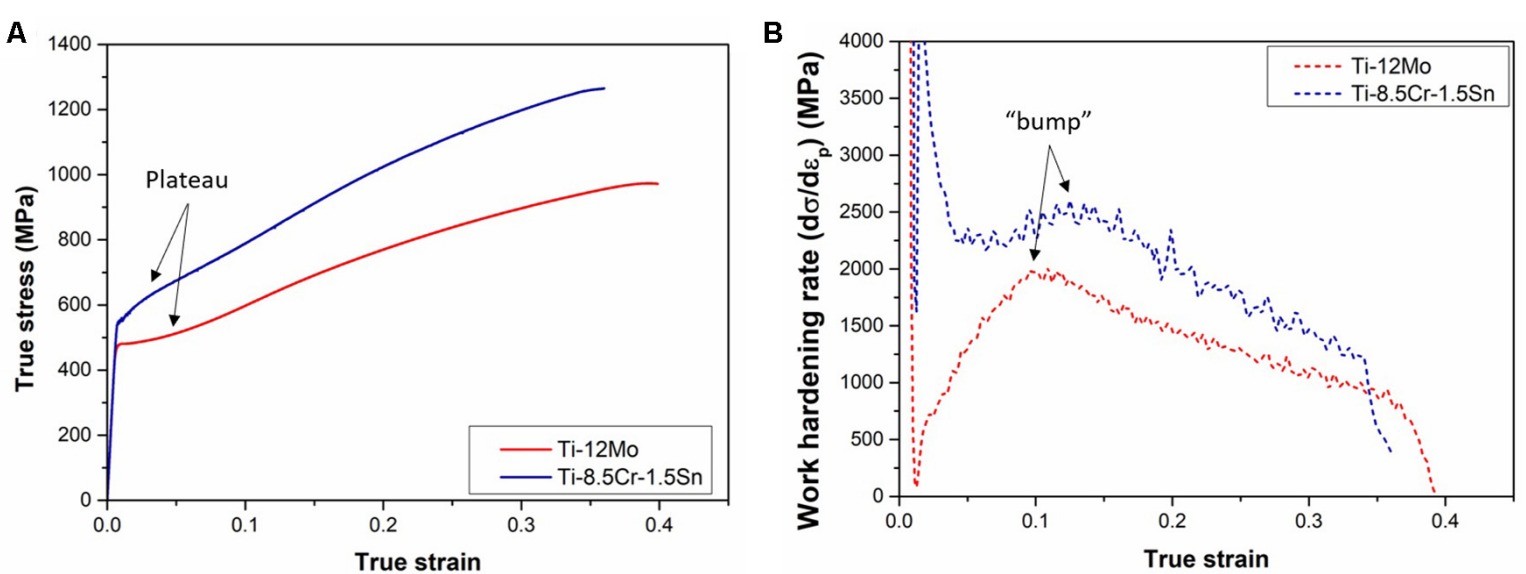

FIGURE 4 | (A) True stress-true strain curves of Ti-12Mo (in red) and Ti-8.5Cr-1.5Sn (in blue) and (B) corresponding strain-hardening rate curves. 
TABLE 2 | Tensile properties at room temperature for a $1.7 \times 10^{-3} \mathrm{~s}^{-1}$ strain rate of the Ti-12Mo and the Ti-8.5Cr-1.5Sn alloys.

\begin{tabular}{lcccc}
\hline Alloy (wt\%) & $\mathbf{E}(\mathbf{G P a})$ & $\boldsymbol{\sigma}_{\mathbf{0 . 2}}$ (MPa) & $\mathbf{R m}(\mathbf{M P a})$ & $\boldsymbol{\varepsilon}_{\text {uniform }}$ \\
\hline Ti-12Mo & 83 & 550 & 1265 & 0.36 \\
Ti-8.5Cr-1.5Sn & 81 & 480 & 970 & 0.4 \\
\hline
\end{tabular}

(nucleation and/or growth) to reach a high-volume fraction of twinned crystal.

\section{In situ EBSD Observations of the "Twinability Mode" in Both Alloys}

As often reported in the literature, mechanical twinning appears to be the main origin of strain-hardening in TRIP/TWIP titanium alloys, by dynamical reduction of the mean free path of dislocation (Rusakov et al., 2006; Marteleur et al., 2012; Min et al., 2013; Brozek et al., 2016; Ren et al., 2018). In order to better understand the specific twin contribution (beyond the classical twinning-fraction parameter) to the strain-hardening rate, in situ monitoring of the deformation has been performed (at the same stages of strain: 5, 7, and 10\% in loaded conditions and 15\% after unloading), using EBSD, for both alloys with a special focus on mechanical twinning and twin-size evolution, as a function of external strain. To be able to consistently compare results, several conditions have been fixed:

(1) As a few studies report an homothetic relationship between grain size and twin width (Beyerlein et al., 2010; Ghaderi and Barnett, 2011; Li et al., 2019), thermal treatments have been adapted for both alloys to reach similar grain size $(\sim 100 \mu \mathrm{m})$.

(2) Measured twin width depending on the grain orientation, grain orientations have been selected to be similar and close to $<111>$ ( $\gamma$ fiber, blue color on the inverse pole figure along normal direction) for observations.

(3) Observed grains have been chosen for their high Schmid factors with respect to the $\{332\}<113>$ twinning system. Therefore, all studied grains have similar orientation along the normal direction ( $\gamma$ fiber) and an orientation close to $45^{\circ}$ along the rolling direction. Similarly, a similar grain environment (texture) has been selected for observations.

Electron backscatter diffraction maps and the corresponding image qualities are presented in Figures 5, 6 for Ti-12Mo and $\mathrm{Ti}-8.5 \mathrm{Cr}-1.5 \mathrm{Sn}$ alloys, respectively. Red lines represent a CSL (coincidence site lattice) $\Sigma 11$ interface, corresponding to $\{332\}<113>$ twin boundaries, and confirm the Schmid factors predictions; that is, selected grains deform mainly by a TWIP effect. It can also be noted that some $\alpha$ " bands can be observed on the Ti-12Mo EBSD maps (blue interfaces on Figure 5), but exhibiting a small Schmid factor with respect to external stress. It may be postulated that martensite in these grains is created to accommodate internal stress, as highlighted by Danard et al. (2019). Comparison of Figures 5, 6 allows highlighting two different behaviors. The applied stress seems to be mainly accommodated by twin growth for Ti-12Mo. At the opposite,

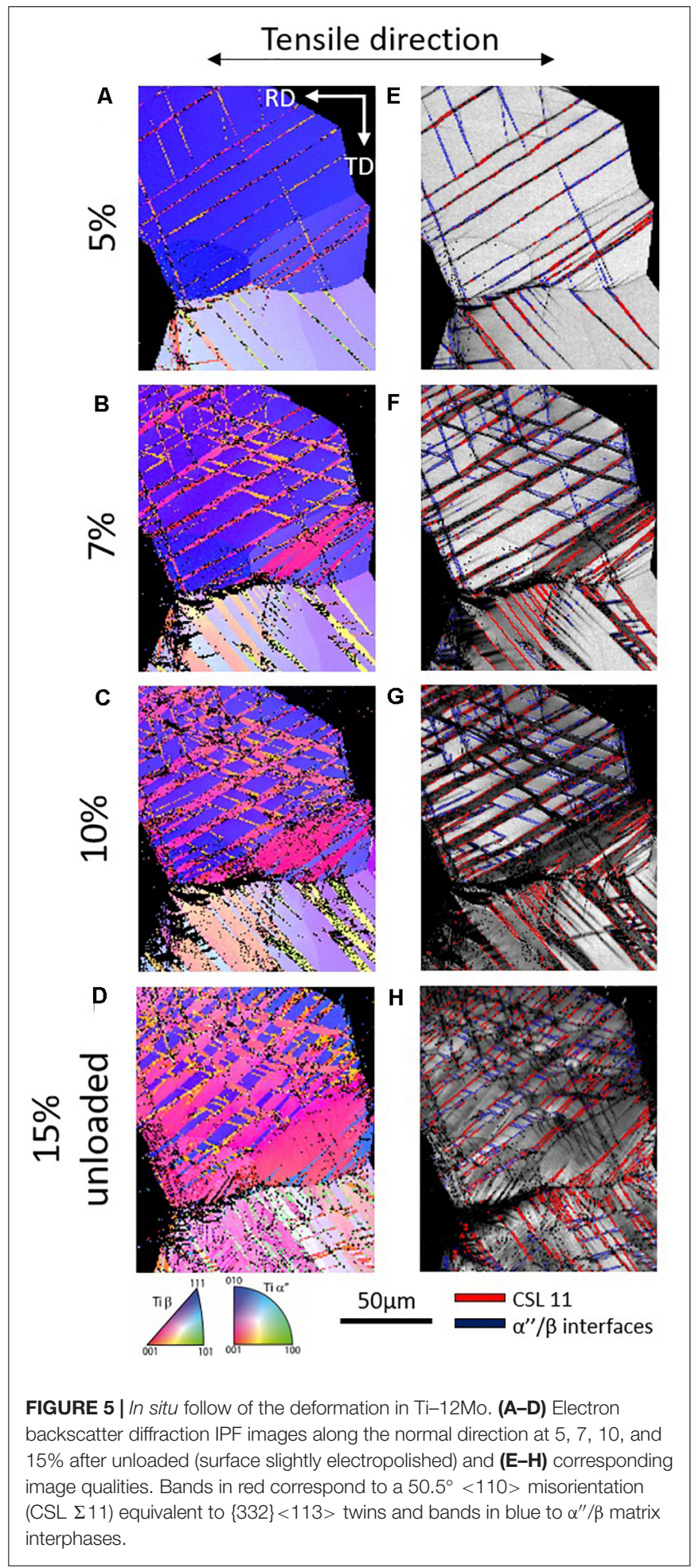

the nucleation mechanism appears to be favored in $\mathrm{Ti}-8.5 \mathrm{Cr}-$ $1.5 \mathrm{Sn}$, resulting in a high quantity of twins/matrix interfaces, at higher strain levels and despite an apparently smaller twinned area fraction.

To quantify more precisely these evolutions, several parameters have been measured using image analysis. Thereby, 


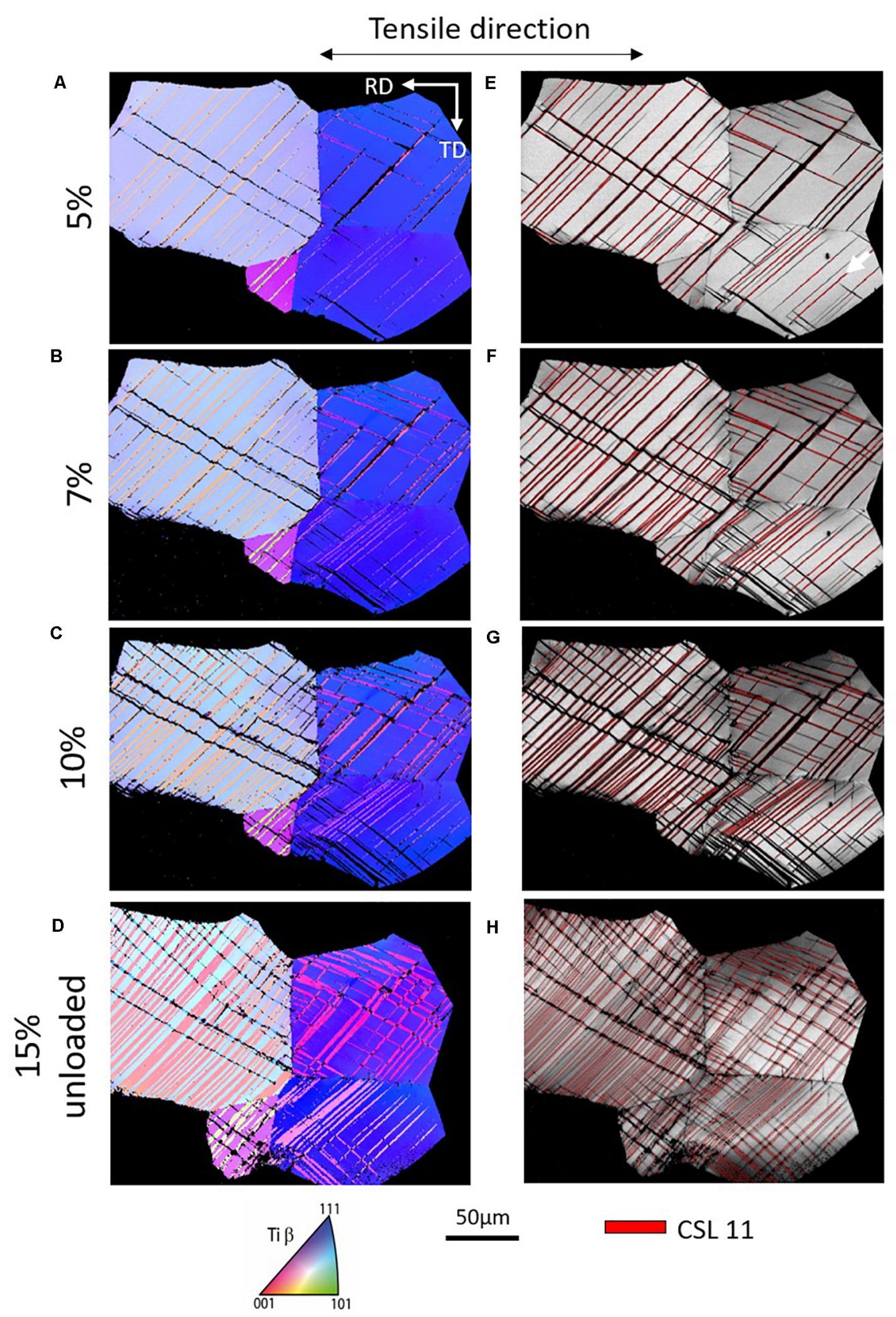

FIGURE 6 | In situ follow of the deformation in Ti-8.5Cr-1.5Sn. (A-D) Electron backscatter diffraction IPF images along the normal direction at 5, 7, 10, and 15\% after unloaded (surface slightly electropolished) and $\mathbf{( E - H )}$ corresponding image qualities. Bands in red correspond to a $50.5^{\circ}<110>$ misorientation $(\mathrm{CSL} \Sigma 11)$ equivalent to $\{332\}<113>$ twins. 
three parameters have been measured to evaluate twin-size evolution:

(1) the length of twin/matrix interfaces by surface unit (in $\mu \mathrm{m}^{-1}$ ), estimated from the length of CSL $\Sigma 11$ lines (in $\mu \mathrm{m}$ ) given by the OIM software and the size of grains (in $\mu \mathrm{m}^{2}$ ) by image analysis using the ImageJ software

(2) the average fraction of twinned surface per grain, measured by the ImageJ software

(3) the average number of twins per grain at equal surface areas using the ImageJ software

The results are reported in Figure 7, in red for $\mathrm{Ti}-$ $12 \mathrm{Mo}$ and in blue for $\mathrm{Ti}-8.5 \mathrm{Cr}-1.5 \mathrm{Sn}$. The low quality of indexation in some areas (mainly for higher deformation rates) induces inevitably some uncertainties; nevertheless, some clear tendencies can be highlighted.

Figure 7A shows that the length of interfaces per surface unit is much higher for $\mathrm{Ti}-8.5 \mathrm{Cr}-1.5 \mathrm{Sn}$ that for $\mathrm{Ti}-12 \mathrm{Mo}$, all along the strain range. For $\mathrm{Ti}-8.5 \mathrm{Cr}-1.5 \mathrm{Sn}$, it increases at the beginning, and then it starts to stabilize at $10 \%$. At the opposite, for $\mathrm{Ti}-12 \mathrm{Mo}$, the length of interfaces per surface unit increases slightly up to $7 \%$ of strain and then decreases. Consequently, at $15 \%$ of strain, this parameter is five times lower in $\mathrm{Ti}-12 \mathrm{Mo}$ than in $\mathrm{Ti}-8.5 \mathrm{Cr}-1.5 \mathrm{Sn}$. The decrease of interfaces quantity in $\mathrm{Ti}-12 \mathrm{Mo}$ can be explained by the fact that twins grow quickly and just start to coarsen at $7 \%$ strain, as it can be seen in Figure 5B. A similar phenomenon is also visible for $\mathrm{Ti}-8.5 \mathrm{Cr}-1.5 \mathrm{Sn}$ but only for a strain of $15 \%$ (Figure 6D), explained by the fact that twins widen less in this alloy compared to $\mathrm{Ti}-12 \mathrm{Mo}$. For $\mathrm{Ti}-12 \mathrm{Mo}$, it can be reasonable to consider that after $15 \%$ of strain the grain shows the tendency to be fully twinned. This coarsening also allows explaining the reduction of number of twins per grain in Figure $7 \mathrm{C}$, where it starts to decrease at $7 \%$ for $\mathrm{Ti}-12 \mathrm{Mo}$ and at $15 \%$ for $\mathrm{Ti}-$ $8.5 \mathrm{Cr}-1.5 \mathrm{Sn}$. Nevertheless, the number of twins per grain for the studied grains is twice lower for $\mathrm{Ti}-12 \mathrm{Mo}$ than for $\mathrm{Ti}-8.5 \mathrm{Cr}-$ $1.5 \mathrm{Sn}$ all over the studied strain range. The combination of a low number of interfaces and twins per grain for $\mathrm{Ti}-12 \mathrm{Mo}$ seems to confirm that a growth mechanism is favored to accommodate the applied stress. At the opposite, twins seem to multiply by additional nucleation for $\mathrm{Ti}-8.5 \mathrm{Cr}-1.5 \mathrm{Sn}$ as it is indicated by the high density of interfaces and twins per grain, suggesting that the favored deformation mechanism is new twin nucleation in this alloy. These suggestions are corroborated by the fact that, starting from the same percentage of twinned surface per grain at $5 \%$ of strain, the total area fraction of twins will increase much more for Ti-12Mo (Figure 7B), without an increase of twin boundaries density.

These observations show that two mechanisms, twin growth and twin multiplication, coexist but may be in competition during deformation:

(1) The growth of twins appears to be the favored mechanism for $\mathrm{Ti}-12 \mathrm{Mo}$, as it can be concluded from the rather low increase of twin/matrix interfaces length and number of twins during the deformation as opposed to the high quantity of twinned surface per grain.
(2) The applied stress seems to be mainly accommodated by twin nucleation during deformation for $\mathrm{Ti}-8.5 \mathrm{Cr}-1.5 \mathrm{Sn}$, with a large increase of the length of interfaces and of the number of twins per grain.

For both alloys, it also fits correctly with the evolution of strain-hardening rates. Indeed, hypothesis can be made that, if nucleation is the promoted mechanism, it leads to the creation of a great number of new interfaces, greatly enhancing the dynamic Hall-Petch effect with a correlated increase of the strain-hardening, as it appears to be the case for $\mathrm{Ti}-8.5 \mathrm{Cr}-1.5 \mathrm{Sn}$ (Rusakov et al., 2006; Marteleur et al., 2012; Brozek et al., 2016; Ren et al., 2018). On the contrary, if the growth of twins is the favored accommodation mechanism, the number of interfaces will not increase during deformation, leading to a minor mean free path decrease and thereby leading to a moderate strainhardening rate, such as for $\mathrm{Ti}-12 \mathrm{Mo}$. Altogether, the remaining question is to understand how one of these two deformation mechanisms can be alternatively favored, depending on the studied alloy but considering an isostability assumption for the $\beta$ phase (with respect to $\mathrm{Bo} / \mathrm{Md}$ electronic parameters).

\section{Strain-Hardenability of TRIP/TWIP Titanium Alloys: Twin Growth Versus Nucleation}

The main twinning system activated in TRIP/TWIP titanium alloys is well-known to be the $\{332\}<113>$ system. However, its mechanism of formation is still unclear. Two main models have been proposed: a mechanism involving shear then shuffle of atoms (Crocker, 1962) or a model of pole dislocation mechanism involving partial dislocations sliding (Rusakov et al., 2006). The second one is in adequacy with Cottrell and Bilby's theory of twin nucleation and growth (Cottrell and Bilby, 1951). They propose that twins are generated by the motion of partial dislocations into the twinning plane. When the first twin layer is created, twins then grow by the propagation of partial dislocations in the neighboring planes. This theory is applied to $\{332\}<113>$ system by Rusakov et al. (2006), who proposed a successive slip of partial dislocations $a / 22<113>$ in pairs of neighboring $\{332\}$ surfaces followed by a reshuffling of atoms of these two planes toward each other in direction $\pm \mathrm{a} / 22<332>$.

Even if the mechanism of $\{332\}<113>$ is still not fully understood, two mechanisms of twin evolution may be highlighted. As proposed by Cottrell and Bilby (1951), twin growth should be easier than nucleation of a new one as the formation of the first layer requires more stress than the subsequent growth of successive layers. However, Sumino (1966) highlights the fact that twins, during their propagation, may meet defects, as other dislocations, precipitates, or solute atoms, which will limit the mobility of interfacial dislocations and subsequently their growth velocity. The local stresses induced by these defects may increase the stress, which is necessary for existing twins to grow, and as a consequence, the twin growth will be delayed. In order to continue to accommodate external stress, nucleation of new twins may be then favored (Sumino, 1966).

These hypotheses may allow a simplified consideration of twin evolution during straining, despite the high complexity 
A

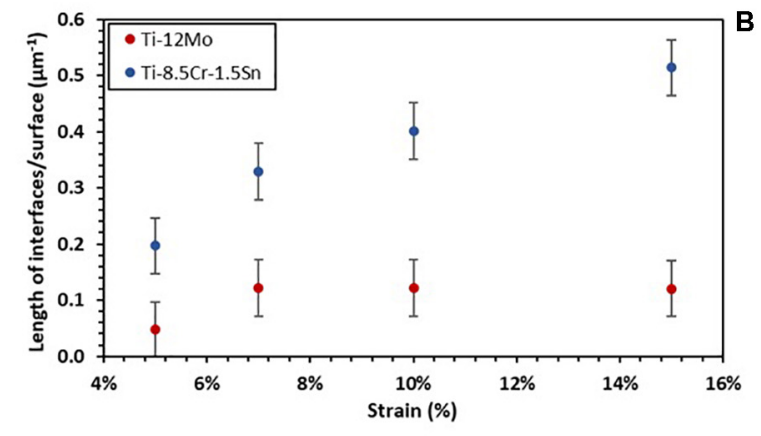

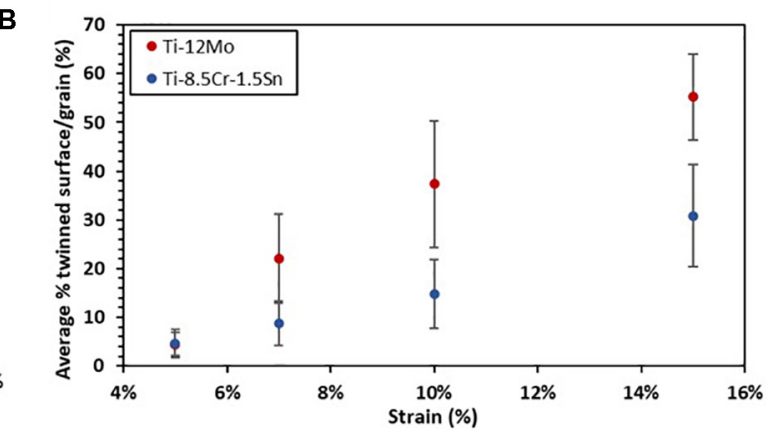

C

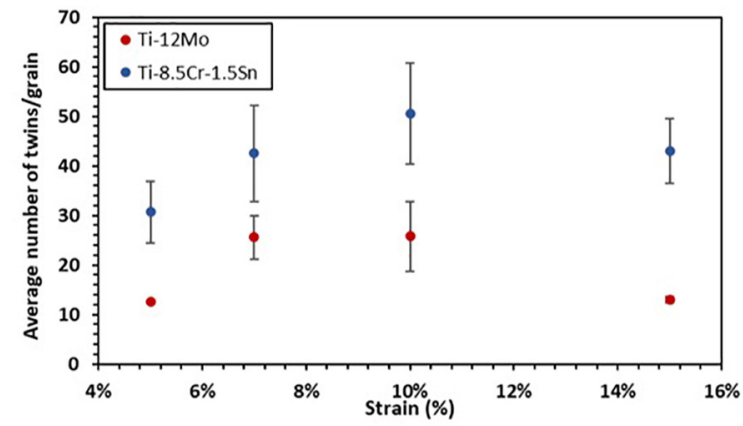

FIGURE 7 | Evolution of (A) length of interfaces per surface unity, (B) percentage of twinned surface per grain, and (C) average number of twins per grain for Ti-12Mo (in red) and Ti-8.5Cr-1.5Sn (in blue).

of activated mechanisms during mechanical twinning. Indeed, it may be supposed that, starting from an initial state where twins have been created (as on the first stage of strain on the studied alloys on Figures 5, 6), two internal mechanisms are in competition to accommodate the applied stress. On one hand, if the mobility of interfacial dislocations is not limited, accommodation will be done by twin growth because it is supposed to be the easiest mechanism (Cottrell and Bilby, 1951), such as for Ti-12Mo, and on the other hand, if the mobility of interfacial dislocations is somehow limited through short range interactions with local elastic fields, for example, accommodation will mainly be accomplished by nucleation of new twins, as for Ti-8.5Cr-1.5Sn. Competition between these two accommodation mechanisms can then be correlated to the strain-hardening rate, as it was proposed previously.

\section{Toward Complementary Parameters in the Design Method of TRIP/TWIP Ti Alloys}

Considering the observations of the twinned microstructures, a competition between two families of behaviors can be assumed: the growth of already existing twins (exemplified by Ti-12Mo) and the nucleation of new mechanical twins to accommodate the external stress (exemplified by Ti-8.5Cr-1.5Sn). From the existing design approach, exclusively based on Bo/Md electronic parameters, this evolution of behavior can hardly be explained because the two alloys can be considered to display a similar chemical stability. This leads to the hypothesis that the design strategies, so far performed for TWIP and/or TRIP effects, are somehow insufficient to predict this kind of character and, as a consequence, the strain-hardenability.

From these first observations, the key concept to explain this evolution of behavior might be the intrinsic mobility of the twins/matrix interfaces. As proposed previously by Sumino (1966), one assumption could rely on the possible solid-solution strengthening effect induced by the chosen alloying elements. In that case, local elastic fields (local distortions of the crystal lattice) due to point defects may interact strongly and therefore limit the mobility of interfacial dislocations and thus the subsequent velocity of twin growth. With this statement, the natural way to reach strain-hardenability by maximization of twins/matrix interface density in TWIP alloys should be to increase the solid-solution strengthening effect for a given level of chemical stability.

TABLE 3 | Atomic radius used in this study for the crystal lattice distortion parameter calculation (Zhang et al., 2014).

\begin{tabular}{ccccc}
\hline & Ti & Mo & Sn & Cr \\
\hline Atomic radius $(p m)$ & 146.15 & 136.26 & 162 & 124.91 \\
\hline
\end{tabular}

TABLE 4 | Crystal lattice distortion parameters calculated for Ti-12Mo and Ti-8.5Cr-1.5Sn.

Alloys (wt\%) Distortion $\delta$ r (\%)

Ti-12Mo

Ti-8.5Cr-1.5Sn 
For this purpose and in order to quantify this crystal lattice distortion, we calculated an average distortion parameter for both alloys, using the following formula proposed by Zhang et al. (2008):

$$
\delta \mathrm{r}=\sqrt{\sum c_{i}\left(1-\frac{r_{i}}{\bar{r}}\right)^{2}} \text { with } \bar{r}=\sum c_{i} r_{i}
$$

where $c_{i}$ is the atomic percentage of the $i$ components; $r_{i}$, the atomic radius of the components; and $\bar{r}$, the average atomic radius. The atomic radii used are listed in Table 3 , and the calculated distortion parameters for $\mathrm{Ti}-12 \mathrm{Mo}$ and $\mathrm{Ti}-8.5 \mathrm{Cr}-$ 1.5Sn are reported in Table 4.

The calculated average distortion parameters display a significant difference, suggesting a much larger solid-solution strengthening effect in $\mathrm{Ti}-8.5 \mathrm{Cr}-1.5 \mathrm{Sn}$ system when compared to Ti-12Mo. This might have a direct effect on the "statistical" dislocations inside the $\beta$-matrix; however, it is well-known that the intrinsic strain-hardening effect is not favorably modified by any solution hardening in the BCC $\beta$-phase in titanium alloys. Instead, a positive effect is expected regarding the evolution of the yield stress, consistently with what observed on the presented stress-strain curves (Figure 3) and with results from the literature for TRIP/TWIP Ti-alloys [see, e.g. (Sadeghpour et al., 2018; Ren et al., 2020)].

According to the results of this study, hypothesis is made that the major effect, with respect to strain-hardening itself, relates to the competition between nucleation and growth of mechanical twins. In materials with strong lattice distortion (such as $\mathrm{Ti}-8.5 \mathrm{Cr}-1.5 \mathrm{Sn}$ ), the nucleation mechanism displays a tendency to become predominant compared to growth of existing twins. This leads to the quick development of a high fraction of new twin/matrix interfaces, which strongly enhances the dynamical Hall-Petch effect, considered as the main strainhardening mechanism.

\section{CONCLUSION}

Altogether, this study gives a new insight on the "twinability mode," which is related to two possible evolutions of twins in competition to accommodate the applied stress. Electron backscatter diffraction analyses coupled with in situ tensile tests allow highlighting the fact that two distinct behaviors are visible during deformation: twin growth or new twin nucleation. Therefore, it may bring additional insights in order to predict more accurately the strain-hardenability

\section{REFERENCES}

Abdel-Hady, M., Hinoshita, K., and Morinaga, M. (2006). General approach to phase stability and elastic properties of $\beta$-type Ti-alloys using electronic parameters. Script. Mater. 55, 477-480. doi: 10.1016/j.scriptamat.2006. 04.022

Beyerlein, I. J., Capolungo, L., Marshall, P. E., McCabe, R. J., and Tomé, C. N. (2010). Statistical analyses of deformation twinning in magnesium. Philos. Magaz. 90, 2161-2190. doi: 10.1080/14786431003630835 of each alloy depending on their chemical composition from additional designing parameters including a "distortion parameter." This parameter is still not quantitative but may be used as an additional "guiding tool," complementary to Bo/Md electronic parameters, with an improved prediction regarding twin evolution. In the course of this work, the "twinability mode" has been "isolated" on purpose, considering similar experimental conditions between the two alloys. However, in addition, it is clear now that TRIP/TWIP titanium alloys generally display heterogeneous microstructures and subsequent additional microstructural parameters that may also influence the global strain-hardening rates, as the TRIP effect (Danard et al., 2019) and the density of statistical dislocations generated that are not considered in this study. Nonetheless, this work highlights the fact that deformation sequences of TRIP/TWIP titanium alloys are not always similar and that the evolution of strainhardening rates may be partially explained by the evolution of twin size depending on the solute-strengthening effect of alloying elements.

\section{DATA AVAILABILITY STATEMENT}

The raw data supporting the conclusions of this article will be made available by the authors, without undue reservation.

\section{AUTHOR CONTRIBUTIONS}

FP designed the research and analyzed the data. YD performed the research and analyzed the data. FS completed the experimental part of the manuscript. TG, IF, and MP provided guidance to this manuscript. YD and FP wrote the manuscript. All authors contributed to the article and approved the submitted version.

\section{FUNDING}

This work was supported by the French National Agency for Research (ANR) in the ANR-15-CE08-0013 TITWIP project. YD and FP are grateful to SAFRAN company for its financial support on the YD Ph.D. grant. IF and MP declare that this study received funding from SAFRAN TECH through the YD Ph.D. grant. The funder was not involved in the study design, collection, analysis, interpretation of the data, the writing of this article or the decision to submit it for publication.

Brozek, C., Sun, F., Vermaut, P., Millet, Y., Lenain, A., Embury, D., et al. (2016). A $\beta$-titanium alloy with extra high strain-hardening rate: design and mechanical properties. Script. Mater. 114, 60-64. doi: 10.1016/j.scriptamat.2015. 11.020

Cottrell, A. H., and Bilby, B. A. (1951). LX. A mechanism for the growth of deformation twins in crystals. Lond. Edinb. Dublin Philos. Magaz. J. Sci. 42, 573-581. doi: 10.1080/14786445108561272

Crocker, A. G. (1962). Twinned martensite. Acta Metallurg. 10, 113-122. doi: 10.1016/0001-6160(62)90056-90051 
Danard, Y., Poulain, R., Garcia, M., Guillou, R., Thiaudière, D., Mantri, S., et al. (2019). Microstructure design and in-situ investigation of TRIP/TWIP effects in a forged dual-phase Ti-10V-2Fe-3Al alloy. Materialia 8:100507. doi: 10.1016/ j.mtla.2019.100507

Gao, J., Huang, Y., Guan, D., Knowles, A. J., Ma, L., Dye, D., et al. (2018). Deformation mechanisms in a metastable beta titanium twinning induced plasticity alloy with high yield strength and high strain hardening rate. Acta Mater. 152, 301-314. doi: 10.1016/j.actamat.2018.04.035

Ghaderi, A., and Barnett, M. R. (2011). Sensitivity of deformation twinning to grain size in titanium and magnesium. Acta Mater. 59, 7824-7839. doi: 10.1016/j. actamat.2011.09.018

Li, Y., Dai, L., Cao, Y., Zhao, Y., and Zhu, Y. (2019). Grain size effect on deformation twin thickness in a nanocrystalline metal with low stacking-fault energy. J. Mater. Res. 34, 2398-2405. doi: 10.1557/jmr.2019.194

Lilensten, L., Danard, Y., Brozek, C., Mantri, S., Castany, P., Gloriant, T., et al. (2019). On the heterogeneous nature of deformation in a strain-transformable beta metastable Ti-V-Cr-Al alloy. Acta Mater. 162, 268-276. doi: 10.1016/j. actamat.2018.10.003

Marteleur, M., Sun, F., Gloriant, T., Vermaut, P., Jacques, P. J., and Prima, F. (2012). On the design of new $\beta$-metastable titanium alloys with improved work hardening rate thanks to simultaneous TRIP and TWIP effects. Script. Mater. 66, 749-752. doi: 10.1016/j.scriptamat.2012.01.049

Min, X., Chen, X., Emura, S., and Tsuchiya, K. (2013). Mechanism of twinninginduced plasticity in $\beta$-type Ti-15Mo alloy. Script. Mater. 69, 393-396. doi: 10.1016/j.scriptamat.2013.05.027

Miyazaki, S., Otsuka, K., and Suzuki, Y. (1981). Transformation pseudoelasticity and deformation behavior in a Ti-50.6at\%Ni alloy. Script. Metallurg. 15, 287292. doi: 10.1016/0036-9748(81)90346-X

Rabadia, C. D., Liu, Y. J., Cao, G. H., Li, Y. H., Zhang, C. W., Sercombe, T. B., et al. (2018a). High-strength $\beta$ stabilized Ti-Nb-Fe-Cr alloys with large plasticity. Mater. Sci. Eng. A. 732, 368-377. doi: 10.1016/j.msea.2018.07.031

Rabadia, C. D., Liu, Y. J., Jawed, S. F., Wang, L., Li, Y. H., Zhang, X. H., et al. (2018b). Improved deformation behavior in Ti-Zr-Fe-Mn alloys comprising the C14 type Laves and $\beta$ phases. Mater. Design 160, 1059-1070. doi: 10.1016/j. matdes.2018.10.049

Rabadia, C. D., Liu, Y. J., Zhao, C. H., Wang, J. C., Jawed, S. F., Wang, L. Q., et al. (2019). Improved trade-off between strength and plasticity in titanium based metastable beta type Ti-Zr-Fe-Sn alloys. Mater. Sci. Eng. A 766:138340. doi: 10.1016/j.msea.2019.138340

Ren, L., Xiao, W., Kent, D., Wan, M., Ma, C., and Zhou, L. (2020). Simultaneously enhanced strength and ductility in a metastable $\beta$-Ti alloy by stress-induced hierarchical twin structure. Script. Mater. 184, 6-11. doi: 10.1016/j.scriptamat. 2020.03.039

Ren, L., Xiao, W., Ma, C., Zheng, R., and Zhou, L. (2018). Development of a high strength and high ductility near $\beta$-Ti alloy with twinning induced plasticity effect. Script. Mater. 156, 47-50. doi: 10.1016/j.scriptamat.2018.07.012
Rusakov, G. M., Litvinov, A. V., and Litvinov, V. S. (2006). Deformation twinning of titanium $\beta$-alloys of transition class. Metal Sci. Heat Treat. 48, 244-251. doi: 10.1007/s11041-006-0078-y

Sadeghpour, S., Abbasi, S. M., Morakabati, M., Kisko, A., Karjalainen, L. P., and Porter, D. A. (2018). A new multi-element beta titanium alloy with a high yield strength exhibiting transformation and twinning induced plasticity effects. Script. Mater. 145, 104-108. doi: 10.1016/j.scriptamat.2017. 10.017

Sumino, K. (1966). Process Controlling The Growth of Deformation Twins, The 1248th Report of The Research Institute for Iron, Steel and Other Metals. 18, 102-115.

Sun, F., Zhang, J. Y., Marteleur, M., Brozek, C., Rauch, E. F., Veron, M., et al. (2015). A new titanium alloy with a combination of high strength, high strain hardening and improved ductility. Script. Mater. 94, 17-20. doi: 10.1016/j.scriptamat.2014. 09.005

Sun, F., Zhang, J. Y., Marteleur, M., Gloriant, T., Vermaut, P., Laillé, D., et al. (2013). Investigation of early stage deformation mechanisms in a metastable $\beta$ titanium alloy showing combined twinning-induced plasticity and transformation-induced plasticity effects. Acta Mater. 61, 6406-6417. doi: 10.1016/j.actamat.2013.07.019

Zhang, Y., Zhou, Y. J., Lin, J. P., Chen, G. L., and Liaw, P. K. (2008). Solidsolution phase formation rules for multi-component alloys. Adv. Eng. Mater. 10, 534-538. doi: 10.1002/adem.200700240

Zhang, Y., Zuo, T. T., Tang, Z., Gao, M. C., Dahmen, K. A., Liaw, P. K., et al. (2014). Microstructures and properties of high-entropy alloys. Prog. Mater. Sci. 61, 1-93. doi: 10.1016/j.pmatsci.2013.10.001

Zhao, G.-H., Liang, X. Z., Kim, B., and Rivera-Díaz-del-Castillo, P. E. J. (2019). Modelling strengthening mechanisms in beta-type Ti alloys. Mater. Sci. Eng. A 756, 156-160. doi: 10.1016/j.msea.2019.04.027

Zhao, G.-H., Xu, X., Dye, D., and Rivera-Díaz-del-Castillo, P. E. J. (2020). Microstructural evolution and strain-hardening in TWIP Ti alloys. Acta Mater. 183, 155-164. doi: 10.1016/j.actamat.2019.11.009

Conflict of Interest: IF and MP were employed by the company SAFRAN TECH.

The remaining authors declare that the research was conducted in the absence of any commercial or financial relationships that could be construed as a potential conflict of interest.

Copyright (c) 2020 Danard, Sun, Gloriant, Freiherr Von Thüngen, Piellard and Prima. This is an open-access article distributed under the terms of the Creative Commons Attribution License (CC BY). The use, distribution or reproduction in other forums is permitted, provided the original author(s) and the copyright owner(s) are credited and that the original publication in this journal is cited, in accordance with accepted academic practice. No use, distribution or reproduction is permitted which does not comply with these terms. 